\title{
An alleged case of assault and murder turned out to be a run over accident
}

\author{
Rathnaweera RHAI ${ }^{1}$, Vidanapathirana $\mathbf{M}^{2}$ \\ Lecturer ${ }^{I}$, Senior Lecturer ${ }^{2}$, Department of Forensic Medicine, Faculty of Medicine, University of Ruhuna, \\ Galle.
}

e-mail address of the corresponding author, Dr. Rathnaweera RHAI:

\section{History}

A 33 year-old male who was returning home with his friends in a bus after enjoying a trip to Kataragama stopped at 'Rathgama' for a cup of tea around 5.30 p.m. They had taken liquor around 3.30 p.m. Few passengers including him had gone into a near by hotel. Inside the hotel, they had an argument followed by a fight with some of the villagers. Most of the visitors including the victim were beaten with clubs and they somehow managed to get back into the bus. Soon after the bus started moving, passengers have realized that the victim was missing and on inspection he was found to be lying on the road behind the bus. He was found to be unconscious and had been admitted immediately to Teaching Hospital, Karapitiya. On admission, he was found to be dead.

At the autopsy, there were grazed abrasions over both knees and forearms, three tram line contusions over limbs and back of the chest (Figure 01-A) and a tire mark on back of the chest (Figure 01-B) with massive crush injuries to chest and abdomen.

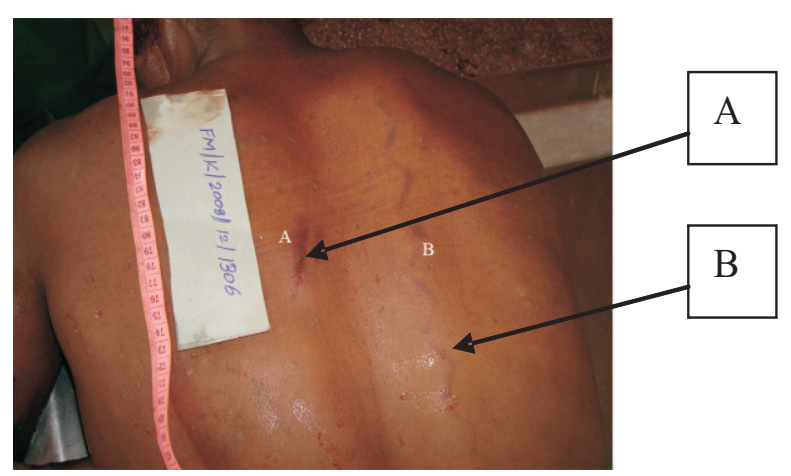

Figure 1 - A photograph of external injuries, A-Tram line contusion, B - Tire mark

\section{Discussion}

The injuries were seen externally and internally, distributed over a wide area, extending from head to toe involving both anterior and posterior aspects of the body. Out of them, surface injuries seemed to be more important to interpret the circumstances. Though there were multiple tram line contusions which are supposed to be resulted only following assault with weapons like clubs ${ }^{1}$, they were found to be non-fatal. The tire mark and the associated internal injuries of the chest and abdomen confirmed a run over ${ }^{2}$ and an instant death.

Absence of an eye witnesses and refusal of allegation of assault and murder by the villagers made it difficult to arrive at the circumstances of the incident. Although there were evidence of blunt force trauma to body by way of tram line contusions, they were proved to be non-fatal. Presence of injuries suggestive of accidental fall and presence of a tire mark with fatal injuries confirmed run over while attempting to get into the moving bus. This excluded the possibility of a murder charge against villagers. This case highlights the value of conducting a meticulous autopsy which includes a careful external examination.

\section{References}

1. Knight B, Saukko P. Knight's Forensic Pathology, $3^{\text {rd }}$ edition, Edward Arnold: Oxford, 2004: 148-9.

2. Di Maio VJM, Dana ES. Hand Book of Forensic Pathology, $1^{\text {st }}$ edition, Texas: Lande Bioscience, 1999: 309-17. 